\title{
The Influence of the Relative Age Effect in the Czech Youth Ice Hockey League
}

\author{
Adrián Agricola', Michal Bozděch², Jiří Zháněl ${ }^{2}$ \\ Affiliations: 'University of Hradec Králové, Faculty of Education, Department of Physical Education and Sports, Hradec \\ Králové, Czech Republic, ${ }^{2}$ Masaryk University, Faculty of Sports Studies, Department of Kinesiology, Brno, Czech \\ Republic
}

Correspondence: A. Agricola, University of Hradec Králové, Faculty of Education, Rokitanského 62/26, 50003, Hradec Králové, Czech Republic. E-mail: adrian.agricola@gmail.com

ABSTRACT The issue of Relative Age Effect (RAE) focuses on the causes and consequences of the failure to respect development patterns of individuals in relation to their success, especially in sports. This study aims to determine whether the influence of the RAE can be proven in the Czech youth ice hockey league (U15) $(\mathrm{n}=744)$. A Chi-Square test $(\chi 2)$ has shown that the influence in the whole investigated group cannot be rejected $(\chi 2=25.34, \mathrm{p}<0.01, \mathrm{w}=0.11)$. The RAE can be rejected in the group of players $(\mathrm{n}=78)$ from the three best teams of the competition $(\chi 2=3.09, \mathrm{p}=0.38, \mathrm{w}=0.11)$; the influence of the RAE can also be rejected in players $(\mathrm{n}=75)$ from the three worst teams $(\chi 2=0.53, \mathrm{p}=0.91, \mathrm{w}=0.05)$. The assessment of $\mathrm{RAE}$ on playing positions has shown that the RAE can be rejected $(\chi 2=7.31, \mathrm{p}=0.06, \mathrm{w}=0.22)$ in the most productive forwards $(\mathrm{n}=50)$ as well as in the least productive forwards $(\mathrm{n}=50)(\chi 2=0.48, \mathrm{p}=0.92, \mathrm{w}=0.06)$. The RAE is rejected in the group of the most productive defensemen $(\mathrm{n}=50)(\chi 2=1.71, \mathrm{p}=0.11, \mathrm{w}=0.11)$, and in the group of the least productive defensemen $(\mathrm{n}=50)(\chi 2=4.15, \mathrm{p}=0.25, \mathrm{w}=0.17)$. The RAE cannot be rejected $(\chi 2=8.88, \mathrm{p}=0.03, \mathrm{w}=0.35)$ in the group of best goaltenders $(n=24)$; the RAE is rejected in the group of the worst goaltenders $(n=24)(\chi 2=1.5, p=0.68, w=0.14)$. Although the results have proven that the RAE cannot be rejected in the entire research group, there is no evidence of its influence (with the exception of the best goaltenders) in individual playing positions.

KEY WORDS birth date, ice hockey, talent, productivity, chronological age

$@ M J S S M o n t e n e g r o$

RELATIVE AGE EFFECT IN CZECH ICE HOCKEY

http://mjssm.me/?sekcija=article\&artid=200

\section{Introduction}

The issue of Relative Age Effect (RAE), also referred to as Birth Date Effect (Karcher, Ahmaidi, \& Buchheit, 2014) or Birth Quarter (Larouche, Laurencelle, Grondin, \& Trudeau, 2010), is the deviation of birth date distribution of selected groups of athletes from the normal frequency distribution in the general population. The results of many studies from the field of sports show that, in particular, athletes in the youth categories born in the first months of the calendar year are often more successful, than those born in the second half of the year. However, it is impossible that more talented athletes would be born during a particular part of the year rather than in another (Lames, Augste, Dreckmann, Görsdorf, \& Schimanski, 2008).

The greater success of chronologically older players is based on the fact that individuals born for instance in January may have a nearly 12-month developmental lead (in terms of physiological, morphological and psychological assumptions), compared to the individuals born in December of the same year (Agricola, Zháněl, \& Hubáček, 2013; Arrieta, Torres-Unda, Gil, \& Irazusta, 2015; Musch \& Grondin, 2001). Athletes born earlier have notably higher levels of strength, endurance, and speed, which enables them to achieve better performance, especially in sports with high demands on their fitness levels. Consequently, these athletes are often identified as above average in selections for fitness-intensive sports. Another reason is the mechanism called the 'vicious circle' (Arrieta et al., 2015; Helsen, Winckel, \& Williams, 2005). Older individuals with an above-average performance are often referred to as talented; therefore, they receive more significant support from their coaches, parents, and friends; this increases their motivation to work harder and to devote more time to the selected sport (Arrieta et al., 2015; Hollings, Hume, \& Hopkins, 2012). However, as the age in- 
creases, the developmental differences equalize, the influence of the RAE weakens (Bjerke, Pedersen, Aune, \& Lorås, 2017; Ford \& Wiliams, 2011; Lames et al., 2008) and the players previously referred to as 'talented' often become only average players. Moreover, many chronologically younger players at this age have already ended their careers (due to burnout syndrome) because of insufficient support to fully develop their potential (Abbot \& Collins, 2004; Arrieta et al., 2015; Peréz \& Pain, 2008). However, the full potential of an athlete (in terms of his/her biological age) may manifest itself up to the age of 21 (Lames, Augste, Dreckmann, Görsdorf, \& Schimanski, 2009). Based on the above, it is clear that the main reason for the emergence of influence of the RAE is the disregard of the different levels of ontogenetic development (biological age) of the athletes as well as the disregard of the significant differences between the athletes born at the beginning, and at the end of the year (calendar, respectively chronological age). In apparently the first study dealing with the influence of the RAE in sports (Grondin, Deshaies, \& Nault, 1984), the authors indicated for the first time the higher representation of chronologically older hockey players and volleyball players. Barnsley, Thompson, and Barnsley (1985) examined hockey players from junior leagues (18-20 years) and from the NHL. The results showed that four times more players among the juniors were born in the first quarter of the year than in the rest of the year. The number was only slightly lower among the NHL players. Grondin (in Musch \& Grondin, 2001) states that in the 1980 s, $40 \%$ of the players playing in the NHL were born in the first quarter, $30 \%$ in the second, $20 \%$ in the third and only $10 \%$ in the last quarter. The significant influence of the RAE in NHL players was explained by Barnley and Thompson (1988) and later by Fumarco, Gibbs, Jarvis, and Rossi (2017) by the fact that the talent selection during the pubescence is significantly affected by the different levels of the biological development of hockey players. Sherar, Baxter-Jones, Faulkner, and Russell (2007) focused on 14-15-year-old hockey players from the Canadian province of Saskatchewan. Because the emphasis was on the body height and overall 'maturity' of hockey players when choosing players for this category, the influence of the RAE could be expected: this was confirmed by the results when the birth frequency curve in individual months had a declining character from January to December. The influence of the RAE in ice hockey has been demonstrated in studies published since 2010 by several authors, for instance, Addona and Yates (2010), Deaner, Lowen, and Cobley (2012), Gibbs, Jarvis, and Dufur (2012), Hancock, Adler, and Côte (2013), Nolan and Howell (2010), Parent-Harvey and Desjardins (2014).

There is currently no known study comparing the influence of the RAE in players of the best and worst teams in a long-term national competition; the researches mostly focus on short-term tournaments of national teams. There is also no known assessment of the influence of the RAE on the long-term productivity for particular player positions in a national competition. Therefore, the first aim of this study was to assess the influence of the RAE in the group of Czech ice hockey players playing in the category of the U15 youth league. The following aim was to determine if the influence of the RAE is stronger in players from the best teams of the competition than in players from the worst teams. We also wanted to learn about the RAE in relation to the success of players in individual positions - defensemen and forwards based on points at the end of the season, and goaltenders based on the number of saves in relation to their time spent on the ice.

\section{Methods}

\section{Participants}

The research group consisted of Czech male ice hockey players born in the years 2001-2002 ( $\mathrm{n}=744)$ playing in the 2016/2017 season of the Czech U15 youth league (ELMD). A total of 30 teams from all over the Czech Republic participated in the competition. The influence of the RAE on the position of the team in the table was assessed based on the birth date of hockey players from the three best teams that had taken part in the final tournament for the title of league champions $(n=78)$ and hockey players from the three worst teams in the table that had finished last in their groups and eventually descended from the league $(n=75)$. When assessing the influence of the RAE in forwards and defensemen, the date of birth of the 50 most productive and the 50 least productive forwards and defensemen, according to the points at the end of the season, were used. To assess the quality of goaltenders, the number of minutes spent on ice in relation to the percentage success of their saves was chosen as the main criterion. During the RAE assessment, the goaltenders were divided by the quartile range into the worst and best quarters. The research group consisted of the 24 best goaltenders and the 24 worst goaltenders of the league. The research data (birth dates) were obtained from the publicly available youth ice hockey website mladeznicky hokej.cz (https://www.hokej.cz/mladez/rozcestnik-souteze).

\section{Procedure}

The inclusion of ice hockey players into individual quarters of the year was performed according to their birth as follows (Qi=quarter): Q1 (January-March), Q2 (April-June), Q3 (July-September), Q4 (OctoberDecember). The analysis of the research data was carried out following the formulation of research questions according to these research criteria: (1) assessment of the influence of the RAE in the entire research group; (2) assessment of the influence of the RAE in the hockey players of the three best and the three worst teams; (3) assessment of the influence of the RAE in the most productive and least productive forwards; (4) assessment of the influence of the RAE in the most productive and least productive defensemen; (5) assessment of the influence of the RAE in the best and worst goaltenders.

\section{Statistical analysis}

To assess the conformity of theoretical (expected) frequency distribution and empirical (observed) frequency 
distribution, the Chi-Square test $(\chi 2)$ in the Goodness of Fit variant was used due to the large group size; data were analysed using the online calculator available on the link: https://www.socscistatistics.com/tests/ goodnessoffit/Default2.aspx.

To assess the effect size for relations between categorical variables (RAE), Cohen's w calculation, was used, which enables to measure the effect size (ES, Cohen, 1988) as small $(\mathrm{w}=0.10)$, medium $(\mathrm{w}=0.30)$ or large $(\mathrm{w}=0.50)$. The theoretical frequency distribution was based on official published data obtained from the data. un.org database. It was based on the data on the number of children born in the year, which was the average value of the birth year of the monitored players. The theoretical data distributions for individual research groups and individual quarters are presented in Table 1. The research data were processed using the STATISTICA 10 software and Microsoft Office - Excel.

\begin{tabular}{ccccc} 
TABLE 1. Theoretical (Expected) Frequency of Hockey Players' Birth Date (\%) \\
Year of birth & $\mathbf{Q}_{\mathbf{1}}$ & $\mathbf{Q}_{\mathbf{2}}$ & $\mathbf{Q}_{\mathbf{3}}$ & $\mathbf{Q}_{\mathbf{4}}$ \\
\hline 2001 & $24.50 \%$ & $26.50 \%$ & $25.80 \%$ & $23.20 \%$ \\
2002 & $24.60 \%$ & $26.30 \%$ & $25.80 \%$ & $23.40 \%$ \\
\hline
\end{tabular}

Note. $Q_{i}=$ quarter of the year.

\section{Results}

The Influence of the RAE in all hockey players

The most hockey players were born in Q1 $(n=226)$ and least in Q4 $(n=128)$. The absolute frequencies of the number of hockey players born in individual quarters $(226 ; 214 ; 176 ; 128)$ have a decreasing tendency, which suggests a possible influence of the RAE in the entire research group. The assessment of the statistical significance of the influence of the RAE using the Chi-Square test (Table 2) showed a statistically significant difference in the distribution of birth data. It can be stated that influence of the RAE in the entire research group of hockey players cannot be rejected, even though the assessment of effect size (ES) showed only a small effect $(w=0.11)$.

\begin{tabular}{|c|c|c|c|c|c|c|c|c|}
\hline Values & $Q_{1}$ & $\mathbf{Q}_{2}$ & $\mathbf{Q}_{3}$ & $\mathbf{Q}_{4}$ & $\mathbf{n}$ & $x^{2}$ & p & w \\
\hline Absolute & 226 & 214 & 176 & 128 & 744 & & & \\
\hline Relative & $30.40 \%$ & $28.80 \%$ & $23.70 \%$ & $17.20 \%$ & $100 \%$ & 25.34 & 0.00 & 0.11 \\
\hline$\Delta$ & 43.0 & 18.3 & -16.0 & -46.1 & $R=89.1$ & & & \\
\hline
\end{tabular}

Note. $x^{2}=$ Chi-Square test; $\mathrm{p}=$ significance level; $\mathrm{w}=$ effect size; $\Delta=$ delta (absolute observed minus absolute expected values); $\mathrm{R}=$ variation range $(\Delta \max -\Delta \min )$.

\section{RAE in hockey players from 3 best and 3 worst teams}

After converting monthly frequencies of hockey players from the three best and three worst teams into individual quarters, the highest frequency was found in Q1 $(n=23)$ and the lowest in Q4 $(n=12)$ in the players of three best teams $(n=78)$. The highest frequency was found in Q2 $(n=21)$ and the lowest in Q1 $(n=16)$ in the players of three worst teams $(n=75)$, which does not support the assumption of the presence of influence of the RAE. Statistical analysis (Table 3) did not show statistically significant differences in the distribution of birth data in any of the examined groups. We reject the influence of the RAE in both research groups of hockey players; the differences between the theoretical and empirical distributions of frequencies are both statistically ( $\mathrm{p}=0.38$ and 0.91 ) and materially $(\mathrm{ES}, \mathrm{w}=0.11$, and $\mathrm{w}=0.05)$ insignificant.

TABLE 3. Comparison of Influence of the RAE in Hockey Players from the 3 Best and the 3 Worst Teams of the Competition

\begin{tabular}{|c|c|c|c|c|c|c|c|c|c|}
\hline Teams & Values & $\mathbf{Q}_{1}$ & $\mathbf{Q}_{2}$ & $\mathbf{Q}_{3}$ & $\mathbf{Q}_{4}$ & $\mathbf{n}$ & $x^{2}$ & $\mathbf{p}$ & w \\
\hline \multirow{3}{*}{$\begin{array}{l}3 \text { best } \\
\text { teams }\end{array}$} & Absolute & 23 & 21 & 22 & 12 & 78 & & & \\
\hline & Relative & $29.50 \%$ & $26.60 \%$ & $28.20 \%$ & $15.40 \%$ & $100 \%$ & 3.09 & 0.38 & 0.11 \\
\hline & $\Delta$ & 3.8 & 0.5 & 1.9 & -6.3 & $R=10.1$ & & & \\
\hline \multirow{3}{*}{$\begin{array}{l}3 \text { worst } \\
\text { teams }\end{array}$} & Absolute & 16 & 21 & 19 & 19 & 75 & & & \\
\hline & Relative & $21.30 \%$ & $28.00 \%$ & $25.30 \%$ & $25.30 \%$ & $100 \%$ & 0.53 & 0.91 & 0.05 \\
\hline & $\Delta$ & -2.5 & 1.3 & -0.4 & 1.5 & $R=4.0$ & & & \\
\hline
\end{tabular}

Note. $\mathrm{X}^{2}=$ Chi-Square test; $\mathrm{p}=$ significance level; $\mathrm{w}=$ effect size; $\Delta=$ delta; $\mathrm{R}=$ variation range.

Forwards

By dividing the monthly frequencies into quarters into the groups of the 50 most productive and the 50 least productive forwards, the highest frequency in Q1 $(n=18)$ and the lowest in Q4 $(n=5)$ was found in the most productive forwards, which suggests a possible influence of the RAE. In contrast, the data distribution in 
individual quarters in the least productive forwards does not suggest any possible existence of influence of the RAE. The highest frequency was found in Q3 $(n=14)$, the lowest in Q1 ( $n=11)$. Results of the statistical analysis of research data (Table 4) of the groups of both most productive and least productive forwards did not confirm the assumption of the influence of the RAE; the differences between the theoretical and empirical distribution of frequencies are statistically ( $\mathrm{p}=0.06$ and $\mathrm{p}=0.92$ ) as well as materially $(\mathrm{ES}, \mathrm{w}=0.22$ and $\mathrm{w}=0.06$ ) insignificant.

TABLE 4. Comparison of the 50 Most Productive and the 50 Least Productive Forwards

\begin{tabular}{|c|c|c|c|c|c|c|c|c|c|}
\hline Position & Values & $\mathbf{Q}_{1}$ & $\mathbf{Q}_{2}$ & $\mathbf{Q}_{3}$ & $\mathbf{Q}_{4}$ & $\mathbf{n}$ & $x^{2}$ & $\mathbf{p}$ & $\mathbf{w}$ \\
\hline \multirow{3}{*}{$\begin{array}{c}\text { Most } \\
\text { productive } \\
\text { forwards }\end{array}$} & Absolute & 18 & 16 & 11 & 5 & 50 & \multirow{3}{*}{7.31} & \multirow{3}{*}{0.06} & \multirow{3}{*}{0.22} \\
\hline & Relative & $36.00 \%$ & $32.00 \%$ & $22.00 \%$ & $10.00 \%$ & $100 \%$ & & & \\
\hline & $\Delta$ & 5.8 & 2.9 & -1.9 & -6.6 & $R=11.3$ & & & \\
\hline \multirow{3}{*}{$\begin{array}{c}\text { Least } \\
\text { Productive } \\
\text { forwards }\end{array}$} & Absolute & 11 & 12 & 14 & 13 & 50 & \multirow{3}{*}{0.48} & \multirow{3}{*}{0.92} & \multirow{3}{*}{0.06} \\
\hline & Relative & $22.00 \%$ & $24.00 \%$ & $28.00 \%$ & $26.00 \%$ & $100 \%$ & & & \\
\hline & $\Delta$ & -1.3 & -1.2 & 1.1 & 1.3 & $R=2.6$ & & & \\
\hline
\end{tabular}

Note. $x^{2}=$ Chi-Square test; $\mathrm{p}=$ significance level; $\mathrm{w}=$ effect size; $\Delta=$ delta; $\mathrm{R}=$ variation range.

\section{Defensemen}

The highest frequency in the group of most productive defensemen was found in Q1, Q2 ( $\mathrm{n}=15)$, and the lowest in Q4 ( $n=9)$; the least productive defensemen had the highest frequency in Q2 ( $n=19)$, and the lowest in Q1 ( $n=9)$. The results of statistical analysis of research data (Table 5) of the groups of the most productive as well as least productive defensemen players enable to reject the assumption of the existence of influence of the RAE. The differences between the theoretical and empirical distribution of frequencies are both statistically $(\mathrm{p}=0.11$ and $\mathrm{p}=0.25)$ and materially $(\mathrm{ES}, \mathrm{w}=0.11$ and $\mathrm{w}=0.17)$ insignificant.

\begin{tabular}{|c|c|c|c|c|c|c|c|c|c|}
\hline Position & Values & $\mathbf{Q}_{1}$ & $\mathbf{Q}_{2}$ & $\mathbf{Q}_{3}$ & $\mathbf{Q}_{4}$ & $\mathbf{n}$ & $x^{2}$ & $\mathbf{p}$ & $\mathbf{w}$ \\
\hline \multirow{3}{*}{$\begin{array}{c}\text { Most } \\
\text { productive } \\
\text { defensemen }\end{array}$} & Absolute & 15 & 15 & 11 & 9 & 50 & \multirow{3}{*}{1.71} & \multirow{3}{*}{0.11} & \multirow{3}{*}{0.11} \\
\hline & Relative & $30.00 \%$ & $30.00 \%$ & $22.00 \%$ & $18.00 \%$ & $100 \%$ & & & \\
\hline & $\Delta$ & -1.3 & -1.2 & -1.9 & -2.6 & $\mathrm{R}=5.4$ & & & \\
\hline \multirow{3}{*}{$\begin{array}{c}\text { Least } \\
\text { productive } \\
\text { defensemen }\end{array}$} & Absolute & 9 & 19 & 10 & 12 & 50 & \multirow{3}{*}{4.15} & \multirow{3}{*}{0.25} & \multirow{3}{*}{0.17} \\
\hline & Relative & $18.00 \%$ & $38.00 \%$ & $20.00 \%$ & $24.00 \%$ & $100 \%$ & & & \\
\hline & $\Delta$ & -3.3 & 5.9 & -2.9 & 0.3 & $\mathrm{R}=9.2$ & & & \\
\hline
\end{tabular}

Note. $\mathrm{X}^{2}=$ Chi-Square test; $\mathrm{p}=$ significance level; $\mathrm{w}=$ effect size; $\Delta=$ delta; $\mathrm{R}=$ variation range.

\section{Goaltenders}

The distribution of absolute frequencies of birth date in individual months in the 24 best and the 24 worst goaltenders was again divided into individual quarters. The best goaltenders were found to have the highest frequency in Q1 $(n=10)$; the zero frequency of birth date in the best goaltenders in Q4 is noteworthy. In the worst goaltenders group, the highest frequency was found in Q2 $(n=8)$, the lowest in Q3 $(n=4)$. Based on the results of the statistical analysis of research data (Table 6) in the group of the best goaltenders, the influence of the RAE cannot be rejected in terms of statistical ( $p=0.03)$ or material $(w=0.35)$ significance. In contrast, the differences between the theoretical and empirical distribution of frequencies in the group of the worst goaltenders are both statistically $(\mathrm{p}=0.68)$ and materially $(\mathrm{ES}, \mathrm{w}=0.14$, small) insignificant.

\section{TABLE 6. Comparison of the Best and Worst Goaltenders}

\begin{tabular}{|c|c|c|c|c|c|c|c|c|c|}
\hline Position & Values & $\mathbf{Q}_{1}$ & $\mathbf{Q}_{2}$ & $\mathbf{Q}_{3}$ & $\mathbf{Q}_{4}$ & $\mathbf{n}$ & $x^{2}$ & $\mathbf{p}$ & w \\
\hline Best qoaltenders & Absolute & 10 & 8 & 6 & 0 & 24 & \multirow{3}{*}{8.88} & \multirow{3}{*}{0.03} & \multirow{3}{*}{0.35} \\
\hline \multirow{2}{*}{$\begin{array}{c}\text { Relative } \\
\Delta\end{array}$} & $41.70 \%$ & $33.30 \%$ & $25.00 \%$ & $0.00 \%$ & $100 \%$ & & & & \\
\hline & 4.1 & 1.6 & -0.2 & -5.6 & $\mathrm{R}=9.7$ & & & & \\
\hline Worst & Absolute & 7 & 8 & 4 & 5 & 24 & \multirow{3}{*}{1.5} & \multirow{3}{*}{0.68} & \multirow{3}{*}{0.14} \\
\hline $\begin{array}{l}\text { goaltenders } \\
\text { Relative }\end{array}$ & $29.20 \%$ & $33.30 \%$ & $16.70 \%$ & $20.80 \%$ & $100 \%$ & & & & \\
\hline$\Delta$ & 1.1 & 1.7 & -2.2 & -0.6 & $R=3.9$ & & & & \\
\hline
\end{tabular}

Note. $X^{2}=$ Chi-Square test; $p=$ significance level; $w=$ effect size; $\Delta=$ delta; $R=$ variation.

\section{Discussion}

The analysis of the influence of the RAE in a group of ice hockey players $(n=744)$ playing Czech youth ice hockey league (U15), showed a statistically significant difference in the distribution of birth data. Therefore, 
it can be stated that the influence of the RAE cannot be rejected in the observed group. The influence of the RAE can be rejected in the group of players from the three best and the three worst teams of the league: the statistical analyses did not show statistically significant differences. The assessment of the RAE for individual player's positions did not show statistically significant differences in forwards and defensemen (applies to both groups- most productive and least productive players). The influence of the RAE can be confirmed only in the group of the best goaltenders; in the group of the worst goaltenders, the influence can be rejected. It should be noted that in both cases for which the influence of the RAE cannot be rejected the ES showed only a small effect.

In the presented study, there are hockey players born in two consecutive years (in this case, 2001 and 2002= in the category of youth players. Hockey players always change after the season: the older year passes to the older players, and the category of U15 players is complemented by the players coming from the category of pupils. This exchange eliminates to some extent the problem that the players from the younger years would not otherwise be involved in the competition. This problem is pointed out in the study by Lames et al. (2008), who demonstrate it on the example of German youth women volleyball players. The age category in their case also includes two years, but the exchange occurs only once every two years, resulting in an extra-strong influence of the RAE.

The annual change in the investigated group of hockey players ensures that it is possible to examine the influence of the RAE in the entire group as a whole, even though it involves two birth years. As already mentioned, only one year from the pupil category is always transferred to the youth category; therefore, the influence of the RAE in younger players is the result of the selection process of this transition. The RAE analysis in the entire group has shown the influence of the RAE, although it is only a weak effect according to the effect size. The result achieved corresponds, for instance, with the study by Hancock et al. (2013), which points to the influence of the RAE in a sample of youth hockey players $(n=25008)$, although states that this effect is no longer as strong as in the categories of pupils. Similar conclusions are given by Lames et al. (2008) on a group of young German hockey players, Sherar et al. (2007) on a group of young Canadian hockey players $(\mathrm{n}=281)$ or Lavoie et al. (2015) who also analysed the investigated group $(n=436)$ by playing positions: the influence of the RAE could not be rejected in forwards and defensemen; the effect was rejected only in the goaltenders.

As mentioned in the introduction, there is currently no known study comparing the influence of the RAE in players of the best and worst teams in long-term national competition. Their conclusions mostly point to a significant influence of the RAE in the best teams, as confirmed for instance by González-Víllora, Pasto-Vicedo, and Cordente (2015) Andrade-Souza, Moniz, and Teoldo (2015) in football (soccer) in the U17 category; Saavedra, Gutiérrez Aguilar, Fernández Romero, Fernandéz Lastra, and Eiras Oliveira (2014) in basketball in the U16 and U17 categories; or Bjørndal, Luteberget, Till, and Holm (2018) in youth handball. The results obtained from the researched group of young hockey players indicate that the hockey players in the three best teams showed no influence of the RAE. Most of the investigated teams had hockey players born in the first three quarters, in which the frequencies were quite balanced. A more significant difference appeared between the third and fourth quarters. This result suggests that it is not necessary for teams to give much preference to older players to succeed in long-term competitions. The opposite situation was in the three worst teams: they had players born predominantly in the second to fourth quarters. The first quarter had the lowest frequency. At the same time, frequencies for individual quarters show that these teams did not have significantly younger players: most players were born in the second quarter of the year (i.e., in the first half of the year), but the teams failed to avert the final descent from the youth league.

An equally interesting result is that the influence of the RAE is rejected in relation to the productivity of both forward and defensemen hockey players, even though the p-value in the category of forwards approached the threshold of statistical significance (0.06). To explain this result, it is again necessary to remember that the category of youth players consists of two years: 2001 and 2002. The hockey players born in 2001 had been playing in the competition for their second year; compared to the 2002 birth year, they are older, more experienced, accustomed to the style, level and demands of the game in this age category. The productivity of the hockey players also often improves in the second year in comparison with the first year. In contrast, the hockey players born in 2002, although dominant in the category of pupils, may not achieve high productivity during the first year. It seems to be likely the consequence why the influence of the RAE is rejected in these groups. The influence is not rejected in the category of the best goaltenders, which means that the goaltenders born in the first months of 2000 or 2001 are given priority. The transition to the higher category does not seem to be such a change for the goaltenders as for the forwards and defensemen players. Therefore, even those who are in the youth category for the first year have a chance to succeed, even at the expense of older goaltenders that have been in this category for the second season.

Several solutions to the RAE have been proposed in the literature; a yearly rotation of athletes might work, which means no two-year age categories. The next recommendation is to create more age categories with smaller bandwidth (Helsen et al., 2005). This change would result in a smaller relative age difference and fewer physical differences between players within any specific age category. The issue of the RAE and the possible consequences of it for the sporting careers of young athletes, especially at the junior level, should also be considered in training programmes. It is essential to change the mentality of youth team coaches (Barnsley \& Thompson, 1988). They should pay more attention to technical and tactical skills when selecting players as 
opposed to an over-reliance on physical characteristics, such as height (Helsen et al., 2005). Only coaches who are fully aware of the struggles of late-born children are prepared to offset the disappointment and setbacks these children encounter (Barnsley, \& Thompson, 1988; Musch, \& Grondin, 2001).

\section{References}

Abbott, A., \& Collins, D. (2004). Eliminating the dichotomy between theory and practice in talent identification and development: considering the role of psychology. Journal of Sport Science, 22(5), 395408. doi: 10.1080/02640410410001675324

Addona, V., \& Yates, P. A. (2010). A closer look at the relative age effect in the National Hockey League. Journal of Quantitative Analysis in Sports, 6(4), 1-17. doi: 10.2202/1559-0410.1227

Agricola, A., Zháněl, J., \& Hubáček, O. (2013). Relative age effect in junior tennis (male). Acta Gymnica, 43(1), 27-33. doi: 10.5507/ag.2013.003

Andrade-Souza, V. A., Moniz, F., \& Teoldo, I. (2015). Relative age effect in FIFA U17 Emirates 2013 World Cup: analysis of players who effectively participated in the matches. Motriz: Revista de Educação Física, 21(4), 403-406. doi: 10.1590/s1980-65742015000400009

Arrieta, H., Torres-Unda, J., Gil, S. M., \& Irazusta, J. (2016). Relative age effect and performance in the U16, U18 and U20 European Basketball Championships. Journal of Sport Science, 34(16), 1530-1534. doi: 10.1080/02640414.2015.1122204

Barnsley, R. H., \& Thompson, A. H. (1988). Birthdate and success in minor hockey: The key to the NHL. Canadian Journal of Behavioural Science, 20(2), 167-176. doi: 10.1037/h0079927

Barnsley, R. H., Thompson, A. H., \& Barnsley, P. E. (1985). Hockey success and birthdate: The relative age effect. Canadian Association for Health, Physical Education, and Recreation, 51(1), 23-28.

Bjerke, Ø., Pedersen, A. V., Aune, T. K., \& Lorås, H. (2017). An inverse relative age effect in male alpine skiers at the absolute top level. Frontiers of Psychology, 8, 1-6. doi: 10.3389/fpsyg. 2017.01210

Bjørndal, C. T., Luteberget, L. S., Till, K., \& Holm, S. (2018). The relative age effect in selection to international team matches in Norwegian handball. PloS one, 13(12), e0209288. doi: 10.1371/journal.pone.0209288

Cohen, J. (1988). Statistical power analysis for the behavioural sciences. 2nd ed. Hillsdale, NJ: Erlbaum.

Deaner, R. O., Lowen, A., \& Cobley, S. (2012). Selection Bias in the National Hockey League: Relatively Younger Players Outperform Their Draft Slots. Available at SSRN 2148627. doi: 10.2139/ssrn.2148627

Ford, P. R., \& Williams, M. A. (2011). No relative age effect in the birth dates of award-winning athletes in male professional team sports. Research quarterly for exercise and sport, 82(3), 570-573. doi: $10.1080 / 02701367.2011 .10599790$

Fumarco, L., Gibbs, B. G., Jarvis, J. A., \& Rossi, G. (2017). The relative age effect reversal among the National Hockey League elite. PloS one, 12(8), e0182827. doi: 10.1371/journal. pone.0182827

Gibbs, B. G., Jarvis, J. A. \& Dufur, M. J. (2012). The rise of the underdog? The relative age effect reversal among Canadian-born NHL hockey players: A reply to Nolan and Howell. International Review for the Sociology of Sport, 47(5), 644-649. doi: 10.1177/1012690211414343

González-Víllora, S., Pastor-Vicedo, J. C., \& Cordente, D. (2015). Relative age effect in UEFA championship soccer players. Journal of Human Kinetics, 47(1), 237-248. doi: 10.1515/hukin-2015-0079

Grondin, S., Deshaies, P., \& Nault, L. P. (1984). Trimestre de naissance et participation au hockey et au volleyball. La Revue Quebecoise de l'Activite Physique, 2: 97-103.

Hancock, D. J., Adler, A. L., \& Côté, J. (2013). A proposed theoretical model to explain relative age effects in sport. European Journal of Sport Science, 13(6), 630-637. doi: 10. 1080/17461391.2013.775352

Helsen, W. F., Winckel, J. V., \& Williams, A. M. (2005). The relative age effect in youth soccer across Europe. Journal of Sport Sciences, 23(6), 629-636. doi: 10.1080/02640410400021310

Hollings, S. C., Hume, P. A., \& Hopkins, W. G. (2012). Relative-age effect on the competition outcomes at the World Youth and World Junior Athletic Championship. European Journal of Sport Science, 14(sup1). S456-S461. doi: 10.1080/17461391.2012.713007

Jiménez, I. P., \& Pain, M. T. (2008). Relative age effect in Spanish association football: Its extent and implications for wasted potential. Journal of Sports Science, 26(10), 995-1003. doi: 10.1080/ 02640410801910285

Karcher, C., Ahmaidi, S., \& Buchheit, M. (2014). Effect of birth date on playing time during international handball competitions with respect to playing positions. Kinesiology, 46(1), 23-32.

Lames, M., Augste, C., Dreckmann, C., Görsdorf, K., \& Schimanski, M. (2008). Der "Relative Age Effect" (RAE): neue Hausaufgaben für den Sport. Leistungssport, 38(6), 4-9.

Lames, M., Augste, C., Dreckmann, C., Görsdorf, K., \& Schimanski, M. (2009). The relative age effect in German youth sports: Football, handball and ice-hockey. E-Journal "Bewegung und Training".

Larouche, R., Laurencelle, L., Grondin, S., \& Trudeau, F. (2010). Influence of birth quarter on the rate of physical activities and sports participation. Journal of Sports Science, 28(6), 627-631. doi: 10.1080/02640411003587392

Lavoie, F., Laurencelle, L., Grondin, S., \& Trudeau, F. (2015). Temporal plasticity of the relative age effect in ice hockey: The case of elite minor players in Québec. International Journal of Applied Sports Sciences, 27(1), 14-25. doi: 10.24985/ijass.2015.27.1.14

Musch, J., \& Grondin, S. (2001). Unequal competition as an impediment to personal development: A review of the relative age effect in sport. Developmental Review, 21(2), 147-167. doi: 10.1006/drev.2000.0516

Nolan, J. E., \& Howell, G. (2010). Hockey success and birth date: The relative age effect revisited. International 
Review for the Sociology of Sport, 45(4), 507-512. doi: 10.1177/1012690210371560 .

Parent-Harvey, C. I., Desjardins, C., \& Harvey, E. J. (2014). Factors affecting the relative age effect in NHL athletes. Canadian journal of surgery, 57(3), 157-161. doi: 10.1503/cjs.008913

Saavedra, M., Gutiérrez Aguilar, Ó., Fernández Romero, J. J., Fernandéz Lastra, D., \& Eiras Oliveira, G. (2014). Relative age effect in lower categories of international basketball. International review for the sociology of sport, 49: 526-535. doi: 10.1177/ 1012690212462832

Sherar, L. B., Baxter-Jones, A. D., Faulkner, R. A., \& Russell, K. W. (2007). Do physical maturity and birth date predict talent in male youth ice hockey players? Journal of Sport Science, 25(8), 879-886. doi: $10.1080 / 02640410600908001$ 